Journal for ImmunoTherapy of Cancer

\title{
Sensitive manipulation of CAR T cell activity using a chimeric endocytosing receptor
}

\author{
Boning Zhang (D), John Victor Napoleon, Xin Liu, Qian Luo, \\ Madduri Srinivasarao (1), Philip S Low
}

To cite: Zhang B, Napoleon JV, Liu X, et al. Sensitive manipulation of CAR T cell activity using a chimeric endocytosing receptor. Journal for ImmunoTherapy of Cancer 2020;8:e000756. doi:10.1136/ jitc-2020-000756

- Additional material is published online only. To view, please visit the journal online (http://dx.doi.org/10.1136/jitc2020-000756).

Accepted 18 August 2020

\section{Check for updates}

(c) Author(s) (or their employer(s)) 2020. Re-use permitted under CC BY-NC. No commercial re-use. See rights and permissions. Published by BMJ.

Chemistry, Purdue University System, West Lafayette, Indiana, USA

Correspondence to Professor Philip S Low; plow@purdue.edu

\section{ABSTRACT}

Background Most adoptive cell therapies (ACTs) suffer from an inability to control the therapeutic cell's behavior following its transplantation into a patient. Thus, efforts to inhibit, activate, differentiate or terminate an ACT after patient reinfusion can be futile, because the required drug adversely affects other cells in the patient.

Methods We describe here a two domain fusion receptor composed of a ligand-binding domain linked to a recycling domain that allows constitutive internalization and trafficking of the fusion receptor back to the cell surface. Because the ligand-binding domain is designed to bind a ligand not normally present in humans, any drug conjugated to this ligand will bind and endocytose selectively into the ACT.

Results In two embodiments of our strategy, we fuse the chronically endocytosing domain of human folate receptor alpha to either a murine scFv that binds fluorescein or human FK506 binding protein that binds FK506, thereby creating a fusion receptor composed of largely human components. We then create the ligand-targeted drug by conjugating any desired drug to either fluorescein or FK506, thereby generating a ligand-drug conjugate with $\sim 10^{-9} \mathrm{M}$ affinity for its fusion receptor. Using these tools, we demonstrate that CAR T cell activities can be sensitively tuned down or turned off in vitro as well as tightly controlled following their reinfusion into tumorbearing mice.

Conclusions We suggest this 'chimeric endocytosing receptor' can be exploited to manipulate not only CAR T cells but other ACTs following their reinfusion into patients. With efforts to develop ACTs to treat diseases including diabetes, heart failure, osteoarthritis, cancer and sickle cell anemia accelerating, we argue an ability to manipulate ACT activities postinfusion will be important.

\section{INTRODUCTION}

The use of intact human cells to treat important diseases is attracting considerable attention. Autologous chondrocytes are under investigation for treatment of cartilage defects ${ }^{1}$; induced pluripotent stem cells are being differentiated into islet cells for treatment of diabetes, ${ }^{2}$ cardiomyocytes are being explored for therapy of damaged heart tissue $^{3}$ and retinal cells are being investigated for replacement of defective retinal pigment epithelial cells in patients with macular degeneration. ${ }^{4}$ In the growing field of immunotherapy, dendritic cell vaccines are being exploited for induction of immunity against cancer-specific and virus-specific antigens, ${ }^{5} 6$ and chimeric antigen receptor (CAR) $\mathrm{T}$ cells are being used for targeted elimination of hematopoietic cancers. ${ }^{7}$ While the promise associated with each of these technologies is very encouraging, concerns remain over how sensitively such therapeutic cells can be manipulated following their reintroduction into patients. Thus, will it be possible for genetically modified cell activities to be upregulated or downregulated when changes in their phenotypes are required for success of the therapy? Can differentiation programs of therapeutic stem cells be redirected if the cells begin to stray from their intended destinies? Can transplanted/engineered immune cells be rejuvenated after their activities become suppressed by the tumor microenvironment or can they be terminated when their function becomes counterproductive?

Approaches to these and related problems currently rely on different solutions for each different need. Thus, termination of a cells activity has been largely approached by introduction of a suicide gene that can be activated by an inducer. ${ }^{89}$ Control of a cells functional status has been primarily pursued by engineering control over activation receptors by small molecule inducers. ${ }^{10}$ Inactivation of critical pathways has been recently achieved by induced ubiquination and degradation of essential proteins (eg, Proteolysis targeting chimera, PROTAC). ${ }^{11}$ However, no universal method has been developed that can mediate all of these regulatory changes with a single modification.

We describe a 'chimeric endocytosing receptor' (CER) that can be transfected into any cell type and then exploited to deliver any drug selectively into that cell type following 
A

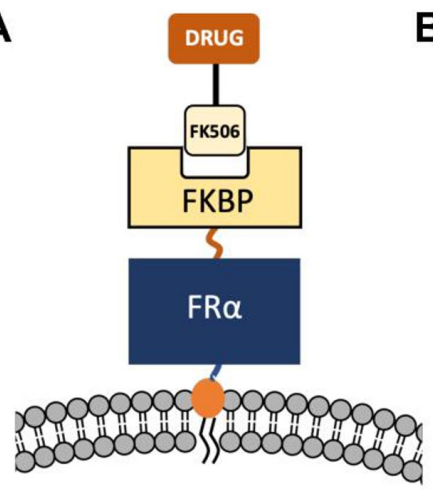

B

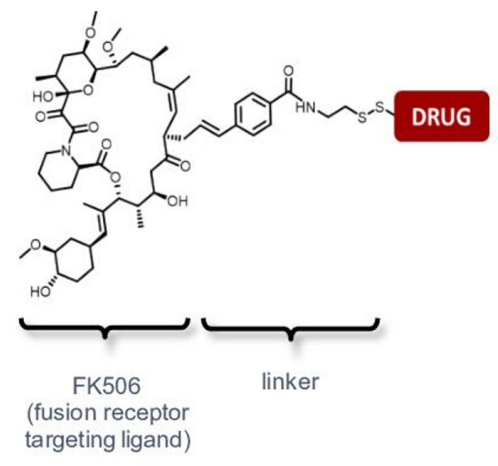

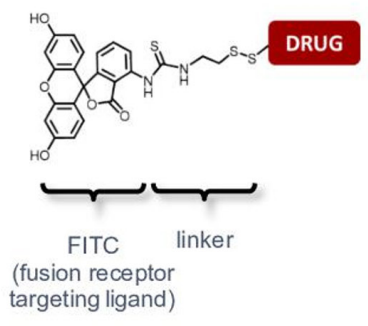

membrane

anchoring

domain

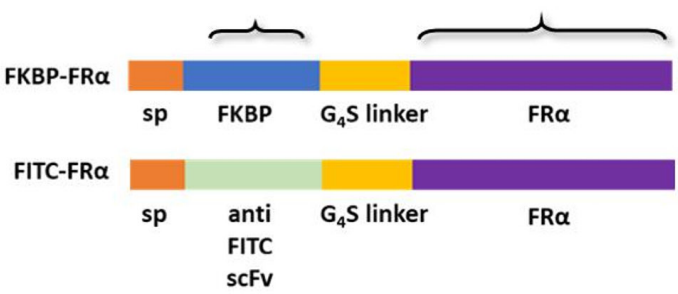

D

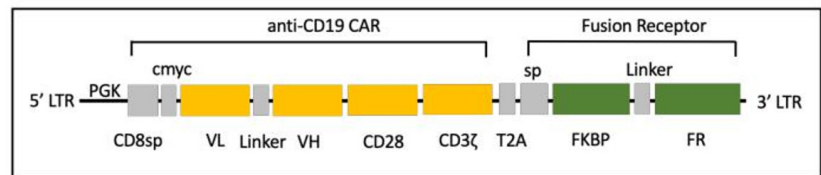

Figure 1 Design of chimeric endocytosing receptors and cognate ligand-drug conjugates. (A) Diagram to show the working mechanism of chimeric endocytosing receptor (CER). In the case illustrated, the fusion receptor is composed of an $\mathrm{NH}_{2}$-terminal FK506 binding protein linked via a glycine ${ }_{4}$-serine spacer to a $\mathrm{COOH}$-terminal glycosylphosphatidylinositol-anchored folate receptor fragment. ${ }^{12}$ Because the fusion receptor contains the high affinity binding site for FK506, conjugation of FK506 to any drug allows the attached drug to enter CER-expressing cells by receptor-mediated endocytosis. (B) Chemical structures of FK506- or FITC-linked conjugates of any desired drug. To avoid causing immunosuppression with FK506-targeted drugs, we have carefully selected the site of attachment of FK506 to its cargo to disrupt FK506 binding to calcineurin while preserving its binding to FKBP12. Note also that the drug is linked to the targeting ligand (FK506 or FITC) via a disulfide bond that is rapidly reduced following trafficking to intracellular endosomes. ${ }^{39}$ (C) Diagram of FKBP-FR and FITC-FR fusion receptor constructs, as described in text. (D) Diagram of anti-CD19 CAR, using FKBP-FR as an example. COOH, C terminal; CD8sp, human CD8 signal peptide; FKBP-FR, FK506 binding protein folate receptor; scFv, short chain variable fragment; sp, human folate receptor alpha signal peptide; T2A, self-cleaving peptide; $\mathrm{VH}$, variable heavy chain; $\mathrm{VL}$, variable light chain.

its reinfusion into a patient in vivo. Construction of this CER simply requires fusion of a protein domain that constitutively endocytoses and recycles to the cell surface (eg, a glycosylphosphatidylinositol (GPI)-anchored folate receptor $(\mathrm{FR}))^{12}$ with a ligand binding domain (eg, FK506 binding protein (FKBP) ${ }^{13}$ or an scFv against fluorescein ${ }^{14}$ ) that exhibits high affinity for a ligand that is not naturally found in humans (figure 1A). Attachment of the desired ligand (ie, FK506 or fluorescein in the above examples) to any drug via a cleavable linker then affords a ligand-drug conjugate that will bind to the CER with high affinity and constitutively enter the transfected cell via receptor-mediated endocytosis (figure 1B). Because both the FR and the FKBP are human in origin, a fusion receptor constructed from these domains should result in minimal immunogenicity. Moreover, since no receptors for either FK506 or fluorescein exist on normal human cell surfaces, little or no drug accumulation should occur in any cell except the cell expressing the transfected receptor. ${ }^{15}{ }^{16}$ Using the human FR $\alpha$ as the constitutively endocytosing domain fused to either a human FKBP or an antifluorescein scFv (scFv FITC) as the ligand-binding domain, we demonstrate that delivery of effective concentrations of both cytotoxic and immunosuppressive drugs can be achieved both in vitro and in vivo via the same CER following its transfection into anti-CD19 CAR T cells.

\section{RESULTS}

Design, expression and characterization of the FKBP-FR and FITC-FR fusion receptors

In order to develop a 'CER' that would allow targeted delivery of any drug into an engineered cell, we hypothesized that the engineered passageway should 
exhibit the following properties. It must (1) be expressed on the cell surface of the desired therapeutic cell, (2) contain a high affinity binding site for a ligand not recognized by any other cell type, (3) endocytose constitutively into the therapeutic cell, (4) recycle rapidly back to cell surface for additional rounds of endocytosis, (5) be assembled from largely human components and (6) exhibit good stability in vivo. With such a receptor expressed exclusively in the therapeutic cell, any desired drug should be deliverable into that cell by linking the drug to a ligand that recognizes the engineered receptor.

In the studies below, two engineered CERs are described that employ either an antifluorescein $\mathrm{scFv}$ (FITC) or FKBP12 as the high affinity ligand binding domain of the fusion receptor (figure 1). Although other binding domains could have been selected, the above two were chosen because they met the criteria described above and exhibited high affinity for their specific ligands (ie, $50 \mathrm{fM}^{14}$ and $0.2 \mathrm{nM},{ }^{13}$ respectively). Moreover, to assure that both ligand binding domains would endocytose constitutively into their engineered cells, each ligand binding domain was tethered via a flexible peptide linker to the GPI-anchored domain of human FR $\alpha$. Because this domain constitutively enters cells by receptor-mediated endocytosis and then rapidly recycles back to the cell surface, ${ }^{12}$ it satisfies the internalization and recycling requirements mentioned above. Further, to promote proper trafficking of de novo synthesized fusion receptors to the cell surface, the N-terminal signal peptide from FR $\alpha$ was attached to the $\mathrm{NH}_{2}$-terminus of the fusion receptor (figure 1C). Finally, in situations where coexpression of a second engineered protein was desired (eg, a CAR), the gene for the CER was ligated via an oligonucleotide encoding the T2A self-cleaving peptide ${ }^{17}$ to the 3 ' end of the gene of the coexpressed protein (figure 1D), that is, ensuring proper expression and independent trafficking of both engineered proteins. ${ }^{18}$ The entire construct was then placed under control of the PGK (phosphoglycerate kinase) promoter of the lentiviral vector.

To determine whether the above CERs might exhibit their intended properties following transfection into target cells in vitro, we expressed both fusion constructs in different cell lines and evaluated their properties. First, the level of expression of the GPI-anchored fusion proteins was assayed in Jurkat $\mathrm{T}$ cells by incubation of the transfected cells with fluorescent dye conjugates of their respective cognate ligands (figure 2A). The number of bound fluorescent conjugates was then measured by flow cytometry. As shown in figure 2B, incubation of the FKBP-FR transfected cells with FK506-rhodamine caused a shift of nearly two orders of magnitude in the mean fluorescence intensity of the transfected Jurkat cells (red line). That this cell-associated fluorescence was bound to the GPI-anchored FKBP-FR could be demonstrated by treating the cells with a GPI-directed phosphoinositide phospholipase C (PI-PLC) and showing that the shift in fluorescence was abrogated (figure 2A, blue line).
Importantly, as seen in the adjacent panel of figure 2A, a similar outcome was obtained when the FITC-FR containing cells were incubated with FITC-AlexaFluor 647.

Next, to obtain a more quantitative measure of the number of CERs expressed in the transfected Jurkat $\mathrm{T}$ cells, we exploited the fact that the fusion receptor also contained a functional binding site for folic acid, that is, allowing the number of FKBP-FR and FITC-FR fusion receptors to be determined by measuring the binding of folate ${ }^{99 \mathrm{~m}} \mathrm{Tc}$ to the transfected cells (figure $2 \mathrm{C}$ ). As shown in figure 2C, the FKBP-FR transfected Jurkat cells bound $\sim 48 \%$ as much folate-targeted radio-imaging agent as FR-expressing KB cells, while the FITC-FR transfected cells bound $\sim 60 \%$ as much as KB cells. Assuming that KB cells express $\sim 3$ million $\mathrm{FR} /$ cell, ${ }^{19}$ the above data suggest that the transfected Jurkat $\mathrm{T}$ cells express between 1.4 and 1.8 million CERs/cell. Because naturally occurring $\mathrm{T}$ cells are more difficult to transduce, the number of CERs that can be expressed on peripheral blood $\mathrm{T}$ cells may be significantly lower. Immunoblots of the transfected cells further demonstrated that the expressed fusion receptors have the anticipated molecular weights of $\sim 50$ and $\sim 60 \mathrm{kDa}$ for FKBP-FR and FITC-FR, respectively (figure 2D).

The affinity of each CER for its cognate ligand was then determined by quantitating FK506-rhodamine or FITCAlexaFluor 647 binding to the same two transfected Jurkat $\mathrm{T}$ cell lines as a function of each conjugate's concentration (figure 3A). Analysis of the derived binding isotherms yielded $K_{d}$ values of $4 \mathrm{nM}$ and $8 \mathrm{nM}$, respectively. Based on prior experience with other ligand-targeted drug conjugates, these affinities should be optimal for drug delivery, since they are sufficiently high to allow receptor saturation at very low systemic concentrations of conjugate in vivo, but not so high that conjugates cannot dissociate from their receptors following endocytosis into their target cells.

To document the generality of CER expression, HEK293 cells were similarly transfected with the FKBP-FR or FITC-FR lentiviral vectors and analyzed for internalization of the fluorescent conjugates by confocal microscopy. As shown in figure $3 \mathrm{~B}$, all of the fluorescence remained on the cell surface at $4^{\circ} \mathrm{C}$ (ie, at a temperature where endocytosis is inhibited), whereas much of the fluorescence became intracellular when cells were incubated at $37^{\circ} \mathrm{C}$ (ie, a temperature where endocytosis is permitted $^{12}$ ). These data demonstrate that the FKBP-FR fusion receptor can internalize with its fluorescent cargo by receptor-mediated endocytosis at $37^{\circ} \mathrm{C}$. Since similar results were obtained when FITC-FR transfected HEK293 cells were incubated with FITC-AlexaFluor 647 (right panels of figure 3B), we conclude that both CERs internalize their bound cargoes at $37^{\circ} \mathrm{C}$, regardless of the structures of the attached drugs.

Next, to quantitate the rates of internalization of the ligand-drug conjugates at $37^{\circ} \mathrm{C}$, we conjugated each ligand to a ${ }^{99 \mathrm{~m}} \mathrm{Tc}$-chelating agent and examined its uptake as a function of time by stripping the cells and gamma 
A

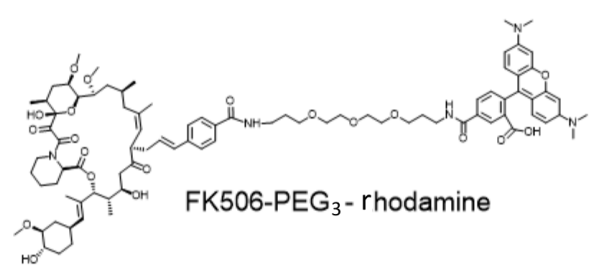

FKBP-FR fusion receptor

B

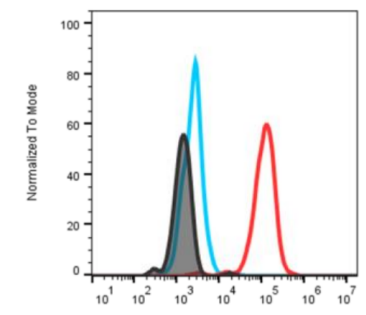

FK506-rhodamine

FKBP-FR cells without staining
FKBP-FR cells labeled with $50 \mathrm{nM}$ FK506-rhodamine
$\mathrm{FKBP}-\mathrm{FR}^{+}$cells treated with PI-PLC and then labeled with $50 \mathrm{nM}$ FK506-rhodamine

C

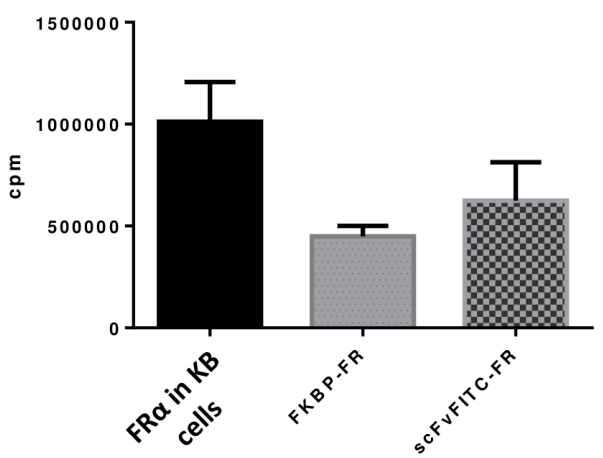

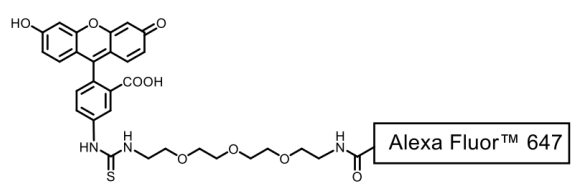

FITC-PEG 3 -Alexa Fluor ${ }^{\text {TM }} 647$

FITC-FR fusion receptor

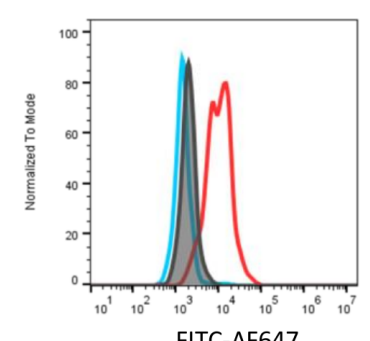

FITC-AF647

FITC-FR+ cells without staining
FITC-FR+ cells labeled with 50 nM FITC-AF647
FITC-FR+ cells treated with PI-PLC and then FITC-FR+ cells treated with PI-PLC
labeled with $50 \mathrm{nM}$ FITC-AF647

D

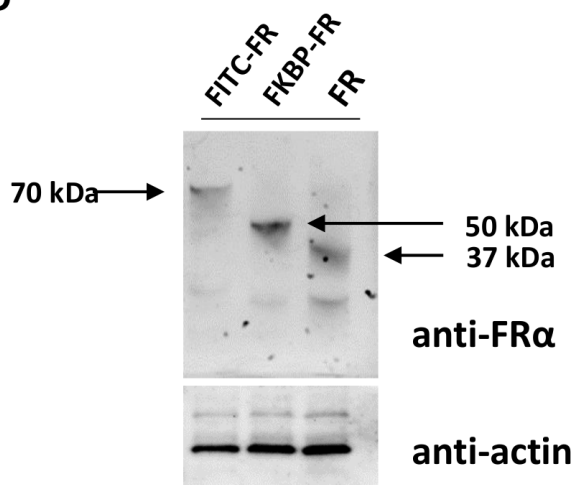

Figure 2 Analysis of ligand-drug conjugate binding to FKBP-FR and FITC-FR fusion receptors. (A) Chemical structures of ligand-drug conjugates (FK506-rhodamine (left) and FITC-AlexFluor647 (right)) used to analyze conjugate binding to CERexpressing cells in vitro. (B) Flow cytometric analysis of FK506-rhodamine (left) and FITC-AlexFluor647 (right) binding to Jurkat cells transfected with FKBP-FR and FITC-FR fusion receptors, respectively. Note that phosphoinositide-specific phospholipase C (PI-PLC) treatment (blue line) cleaves the chimeric endocytosing receptor from the cell surface and thereby abolishes conjugate binding. (C) Relative expression of the two fusion receptors on Jurkat cells compared with expression FR on KB cells, as quantitated by counting of EC20- ${ }^{99 \mathrm{~m}} \mathrm{Tc}$ binding (black bar: FR $\alpha$ in KB cells, gray bar: FKBP-FR in Jurkat cells, hatched bar: FITC-FR in Jurkat cells). Bar graph represents mean $\pm S D, n=3$. (D) Western blot of FITC-FR in Jurkat cells, FKBP-FR in Jurkat cells and FR $\alpha$ in KB cells detected with anti-FR $\alpha$ monoclonal antibody. FKBP-FR, FK506 binding protein folate receptor; $\mathrm{FR} \alpha$, folate receptor alpha.

counting. As shown for the FITC- ${ }^{99 \mathrm{~m}} \mathrm{Tc}$-chelate conjugate in figure $3 \mathrm{C}$, binding of the radioactive conjugate to the FITC-FR HEK293 cells became saturated within an hour at $4^{\circ} \mathrm{C}$, after which uptake leveled off due to the blockade of internalization (figure 3D). In contrast, uptake of the radioconjugate at $37^{\circ} \mathrm{C}$ continued linearly and indefinitely due to constitutive recycling of the fusion receptor back to the cell surface. Based on the difference between the curves at $4^{\circ} \mathrm{C}$ and $37^{\circ} \mathrm{C}$, the rate of intracellular delivery of the ${ }^{99 \mathrm{~m}} \mathrm{Tc}$ conjugate at $37^{\circ} \mathrm{C}$ can be estimated to be $\sim 1000$ molecules/cell $/ \mathrm{min}$.

Finally, the stability of both fusion receptors was examined by comparing their conjugate binding affinities over a period of months. Analyses (data not shown) demonstrate that no change in binding affinity occurred, suggesting that expression of functional fusion receptors could be maintained for prolonged periods of time.

\section{Targeted delivery of therapeutic quantities of drugs to human $T$ cells}

With the ability of the CER to deliver a variety of cargoes to different CER-containing cell lines established, the question next arose whether sufficient quantities of therapeutic drug could be delivered to change cell properties. Because a major need of many CAR T cell therapies has been to terminate the cell's activity when its behavior 

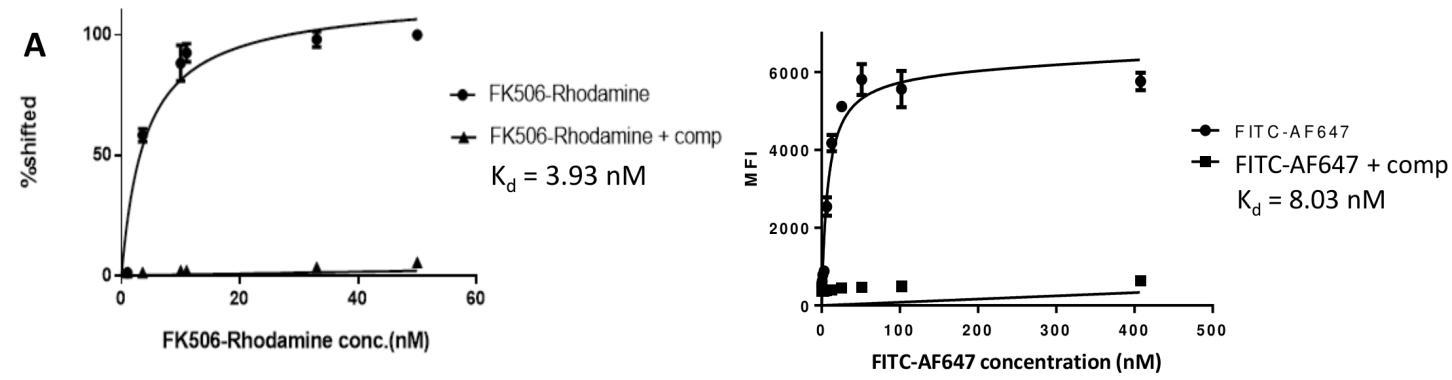

B

$4^{\circ} \mathrm{C}$

$37^{\circ} \mathrm{C} 1 \mathrm{~h}$

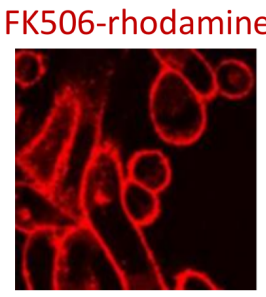

FITC-AF647

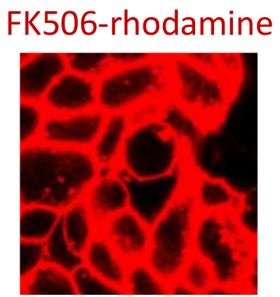

FITC-AF647
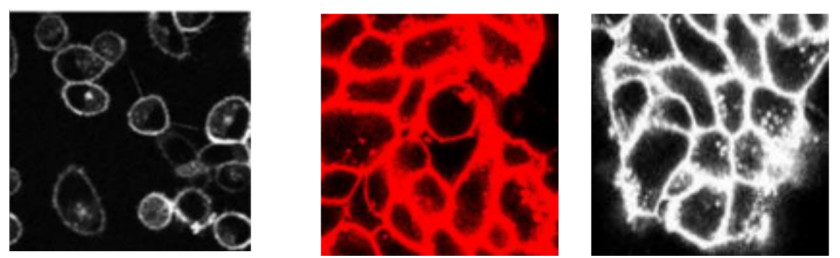

C

D
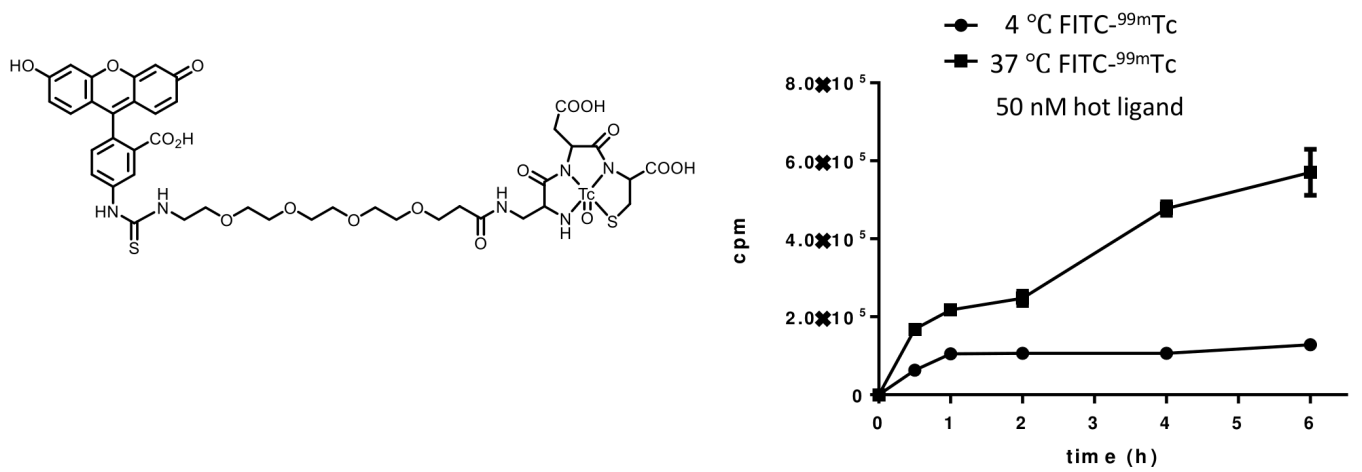

Figure 3 Quantitation of cell surface binding and internalization of ligand-drug conjugates by chimeric endocytosing receptor expressing HEK293 cells. (A) Evaluation of binding of FK506-rhodamine and FITC-AlexFluor 647 to FKBP-FR (left) and FITCFR (right) expressing HEK293 cells in the presence and absence of 100-fold excess competitor (ie, glucosamine conjugates of the respective ligands). MFI: mean fluorescence intensity. (B) Internalization of FKBP-FR and FITC-FR fusion receptors in HEK293 cells at $4^{\circ} \mathrm{C}$ and $37^{\circ} \mathrm{C}$ detected by confocal imaging of the fluorescence of their ligand-dye conjugates, that is, FK506-rhodamine and FITC-AF647, respectively. (C) Chemical structure of FITC- ${ }^{99 \mathrm{~m}}$ Tc conjugate used for radiolabeling of cells expressing FITC-FR fusion receptor. (D) Binding and accumulation of FITC- ${ }^{99 \mathrm{~m}}$ Tc in FITC-FR expressing HEK293 cells. FITC-FR expressing cells were incubated with $50 \mathrm{nM} \mathrm{FITC-}{ }^{99 \mathrm{~m}} \mathrm{Tc}$ at either $4^{\circ} \mathrm{C}$ or $37^{\circ} \mathrm{C}$ for the times indicated, and then radioactivity was determined by gamma counting. Graphs represent mean \pm SD, n=3. FITC-FR, FK506 binding protein folate receptor.

became life threatening, ${ }^{20}$ we undertook to determine whether we could kill CER-expressing $\mathrm{T}$ cells with passageway-targeted cytotoxic conjugate. As shown in figure 4, treatment of FITC-FR transfected fresh human $\mathrm{T}$ cells with a maytansine-FITC conjugate (ie, DM4, a microtubule inhibitor, ${ }^{21}$ conjugated to FITC via a disulfide linker ${ }^{22}$; figure $4 \mathrm{~A}$ ) resulted in killing of the $\mathrm{T}$ cells with an $\mathrm{IC}_{50}$ of $4.2 \mathrm{nM}$. Similar but less potent results were also obtained when an FK506-tethered DM1 conjugate was incubated with FKBP-FR (online supplemental figure S1). Moreover, addition of excess FITC-glucosamine to block maytansine-FITC binding to the anti-FITC CER reduced the conjugate's toxicity $\sim 10$-fold, suggesting that most of the conjugate's uptake was mediated by the CER. Indeed, this conclusion was strengthened by data in online supplemental figure S1 showing that the toxicity of the FK506-DM1 conjugate was similarly suppressed by addition of excess FK506-glucosamine. Taken together, these results demonstrated that suppression of an overactive $\mathrm{T}$ cell can be achieved by killing the $\mathrm{T}$ cell with a CER-targeted cytotoxic drug.

Next, to test whether the CER might be analogously used to reduce a $\mathrm{T}$ cell's activity without killing it, we exploited the same two CERs to deliver FK506, a noncytotoxic immunosuppressant of T cell activity. ${ }^{23}$ As shown in figure 5A, delivery of FK506 to FITC-FR expressing 
A

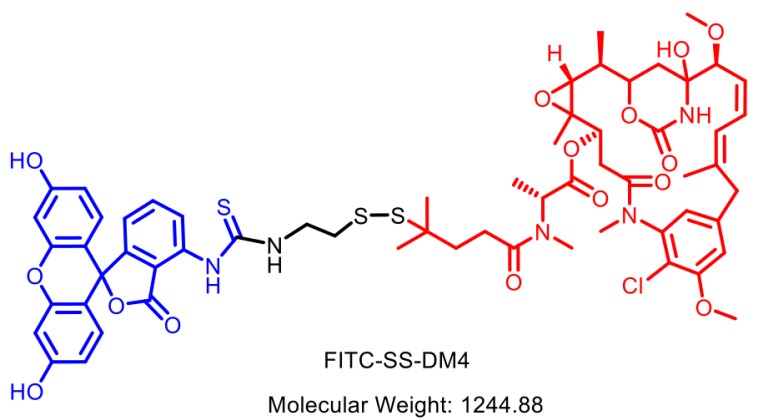

B

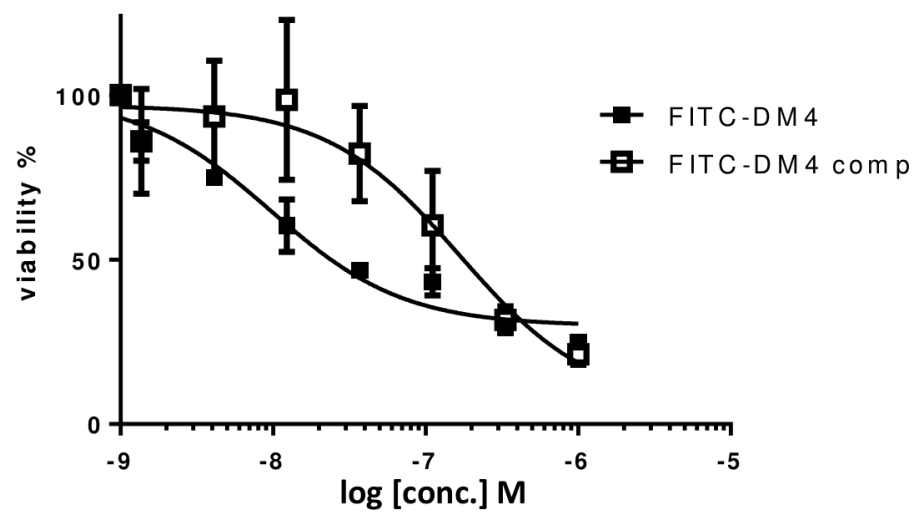

Figure 4 Effect of a FITC-cytotoxic drug conjugate on the viability FITC-FR transfected human T cells. (A) Structure of FITC-maytansine conjugate (FITC-DM4) constructed with a protected self-immolative disulfide releasable linker. Blue: FITC; Black: linker; Red: DM4. This self-immolative linker is designed to remain intact during transit through the vasculature to the chimeric endocytosing receptor expressing cell, but release an unmodified maytansine following endocytosis into a reducing compartment within the targeted cell. ${ }^{22}$ (B) Freshly isolated human T cells were transfected with FITC-FR and then incubated for 2 housr at $37^{\circ} \mathrm{C}$ with different concentrations of FITC-DM4 in the absence or presence of 100 -fold excess competitor (FITCglucosamine). After washing to remove drug conjugates, incubation was continued at $37^{\circ} \mathrm{C}$ for $72 \mathrm{hours}$, and cell viability was determined using an LDH (lactate dehydrogenase) release assay. Graphs represent mean \pm SD, n=3. FITC-FR, K506 binding protein folate receptor

CAR T cells was achieved by constructing a conjugate of FITC linked to FK506 (upper structure), whereas delivery of FK506 to FKBP-FR expressing CAR T cells was attained by synthesizing FK506 linked to FK506 (lower structure). Regardless of the fusion receptor used, increasing doses of targeted drug facilitated enhanced suppression of CAR $\mathrm{T}$ cell activity (figure $5 \mathrm{~B}$ ). Moreover, the immunosuppressive effect of targeted FK506 is significantly reduced when the CERs are blocked by competition with excess ligand (ie, FK506-glucosamine or FITC-glucosamine, online supplemental figure S2). Because no decrease in cell viability was observed during these treatments, we conclude that elevating the concentration of either targeted FK506 conjugate can suppress both CAR T cellmediated lysis of $\mathrm{CD} 19^{+}$Raji cells (figure 5B, top panels) and CAR T cell-derived secretion of interferon (IFN) gamma (figure 5B, lower panels) without loss of viability. This capability should prove generally useful, since

A

B

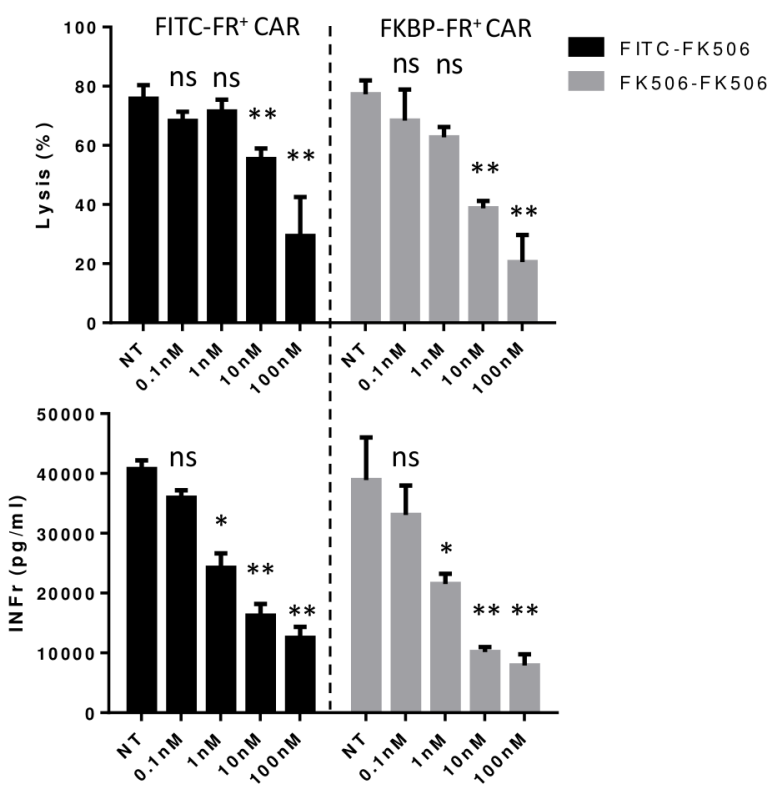

Figure 5 Suppression of anti-CD19 CAR T cell activity following chimeric endocytosing receptor-mediated delivery of non-lethal immunosuppressant conjugates. (A) Chemical structures of FITC-PEG $-F_{3}$ 506 and FK506-PEG - FK506 ligand immunosuppressant conjugates. Blue: targeting ligands FITC (upper panel) or FK506 (lower panel); Black: linker; Red: FK506. (B) Inhibition of FITC-FR or FKBP-FR expressing anti-CD19 CAR T cell lysis of Raji cells (top) and IFN $\gamma$ release (bottom) on incubation for 2 hours at $37^{\circ} \mathrm{C}$ with FITC-FK506 or FK506-FK506, respectively. Following incubation with ligand-drug conjugates, cells were washed to remove drugs and incubation was continued for 12 hours before analyses. Bar graphs represent mean $\pm \mathrm{SD}, \mathrm{n}=3$, * denotes a $p$-value $<0.05,{ }^{* *}<0.01$, ns $=$ not significant. NT, no treatment containing only vehicle control. CAR, chimeric antigen receptor; FKBP-FR, FK506 binding protein folate receptor; IFN $\gamma$, interferon- $\gamma$. 

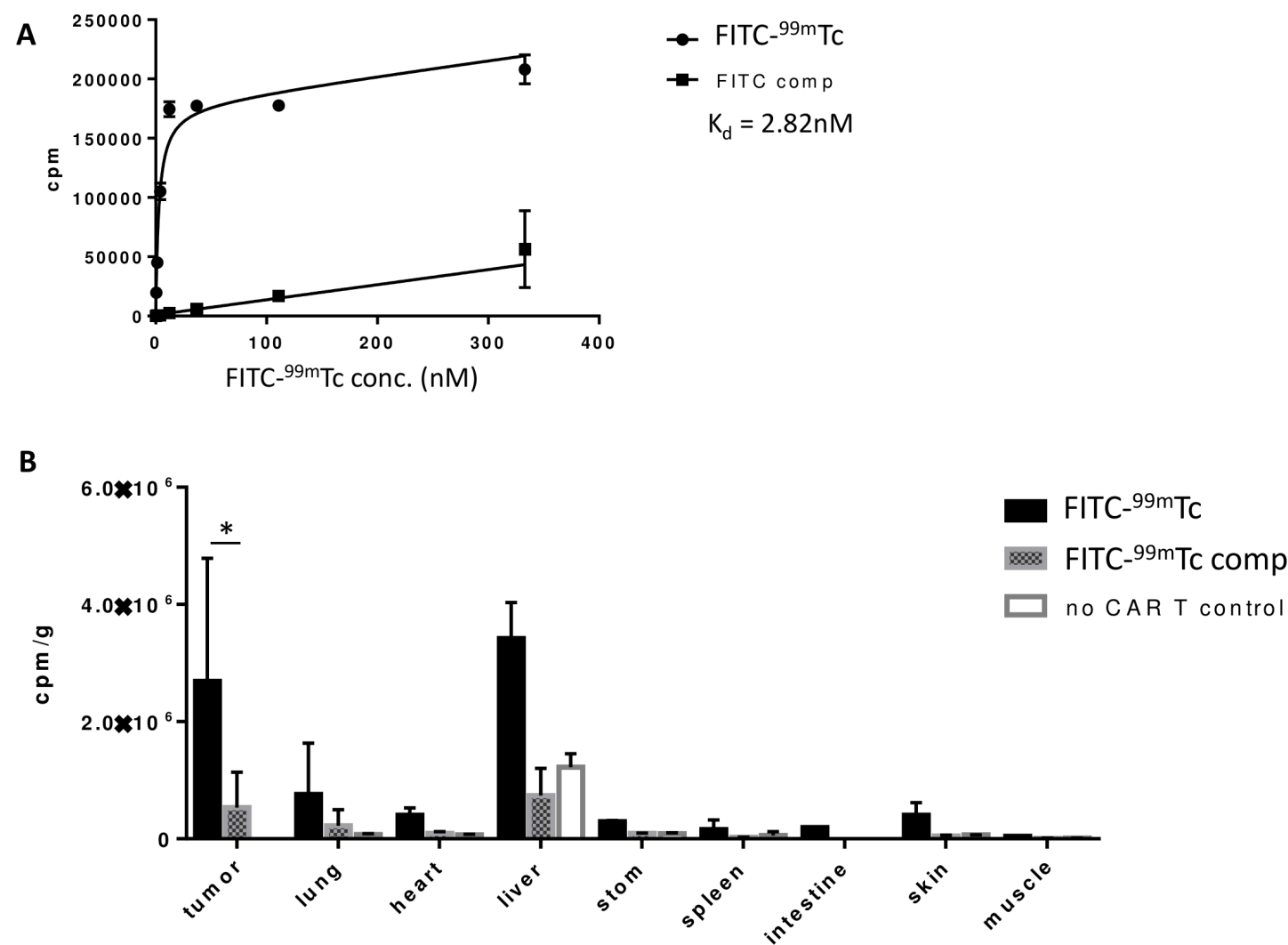

Figure 6 Confirmation of in vivo specificity of FITC as a targeting ligand for drug delivery through FITC-FR chimeric endocytosing receptor. (A) Evaluation of binding affinity of FITC- ${ }^{-99 m}$ TC for FITC-FR fusion receptor in the presence and absence of 100 -fold excess competitor (FITC-glucosamine). (B) Biodistribution of FITC- ${ }^{99 m}$ TC 4 hours post-tail vein injection. Black bars: FITC- ${ }^{99 m}$ Tc; Hatched bars: FITC- ${ }^{99 m}$ Tc plus competition with 100-fold excess cold conjugate; Open bars: no CAR T cells injected; Bar graph represents mean $\pm \mathrm{SD}, \mathrm{n}=3$, ${ }^{*}$ denotes a $p$-value $<0.05$. CAR, chimeric antigen receptor; FITC-FR, FK506 binding protein folate receptor.

control of CAR T cell activity via activation of a suicide gene (ie, the alternative approach to controlling a cytokine storm) will often terminate the immunotherapy.

\section{Control of CAR T cell numbers and/or activities in vivo using a CER}

Next, to evaluate the ability of the CER to enable manipulation of CAR T cell functions in vivo, we prepared CERexpressing CAR $\mathrm{T}$ cells by transfecting fresh human $\mathrm{T}$ cells with an anti-CD19 CAR linked via a self-cleaving T2A peptide to our FITC-FR CER (see the Methods section). After injecting the engineered CAR $\mathrm{T}$ cells into NSG mice bearing CD19-transfected MDA-MB-231 human tumor xenografts, we first explored whether a FITCtargeted ${ }^{99 \mathrm{~m}} \mathrm{Tc}$ radioconjugate (figure $3 \mathrm{C}$ ) might accumulate selectively in the CAR $\mathrm{T}$ cells in vivo. To obtain this information, 14 days after tail vein injection of the CAR $\mathrm{T}$ cells, mice were reinjected with FITC- ${ }^{99 \mathrm{~m}} \mathrm{Tc}$ and then sacrificed 4 hours later in preparation for biodistribution analysis. As shown in figure $6 \mathrm{~A}$, the FITC- ${ }^{99 \mathrm{~m}} \mathrm{Tc}$ conjugate was found to bind to CER-expressing CAR $\mathrm{T}$ cells in vitro with a $\mathrm{K}_{\mathrm{d}} \sim 2.8 \mathrm{nM}$. Moreover, following intravenous injection, the conjugate was seen to accumulate primarily in tumor and liver, with significantly less retention in all other tissues (panels B and C, solid bars). That the vast majority of this tissue retention was CAR T cell-mediated is demonstrated by the observations that (1) FITC- $^{99 \mathrm{~m}} \mathrm{Tc}$ uptake is largely prevented by co-administration of unlabeled conjugate (see hatched bars) and (2) FITC- $^{99 \mathrm{~m}} \mathrm{Tc}$ uptake is essentially absent in all tissues except liver in mice not receiving engineered CAR T cells (open bars). Taken together, these data demonstrate that FITC-linked conjugates accumulate almost exclusively in FITC-FR fusion receptor-expressing CAR $\mathrm{T}$ cells where the only known FITC receptor exists. The fact that some accumulation of FITC- ${ }^{99 \mathrm{~m}}$ Tc remains in livers of mice not receiving CAR T cells is probably due to non-specific uptake of the conjugate by scavenger receptors in the liver. ${ }^{24}$

Finally, to assess the ability of this CER to facilitate control of CAR T cell activity in vivo, NSG (NOD-scid IL2Rg ${ }^{\text {null }}$ ) mice were inoculated intravenously with CD19-expressing Raji cells to mimic a disseminated hematopoietic cancer, and the malignant cells were allowed to proliferate until their numbers exceeded $\sim 8 \%$ of the total white cell count and their body weights decreased by $\sim 10 \%$. Anti-CD19 FITC-FR CAR T cells were then injected and CAR T cellderived (ie, human) IFN $\gamma$ levels were permitted to rise to $>25000 \mathrm{pg} / \mathrm{mL}$ to mimic a cytokine release syndrome (CRS).$^{25}$ The mice were then injected with a single dose of FITC-DM4 to determine whether CAR-mediated uptake of the cytotoxic drug would reduce CAR $\mathrm{T}$ cell numbers 


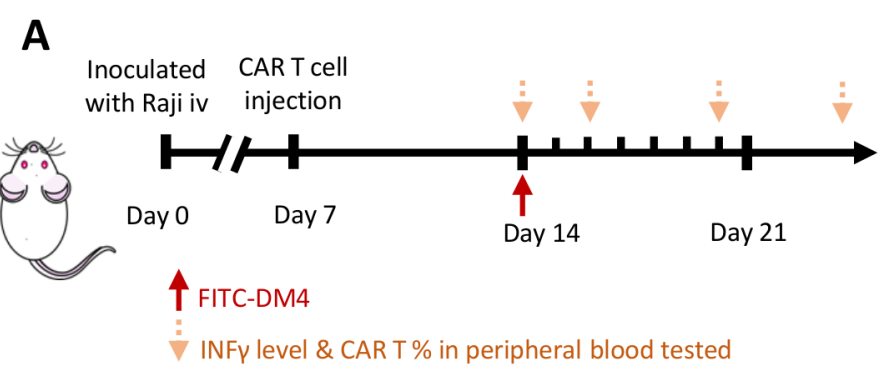

B

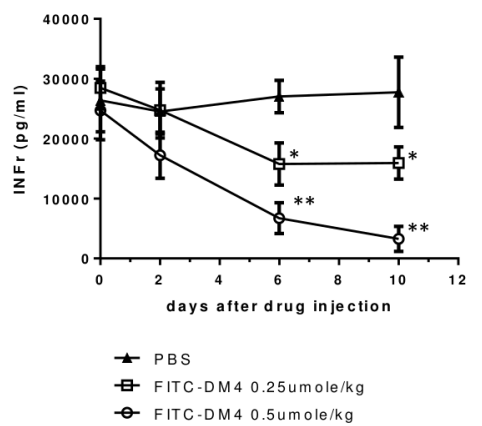

$c$

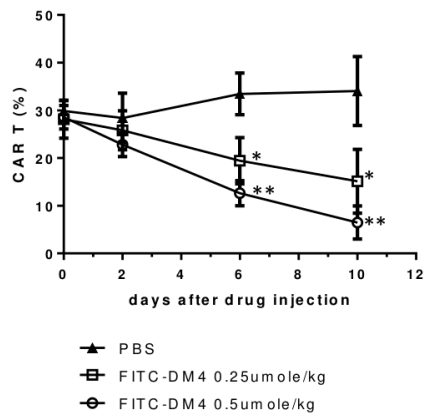

D

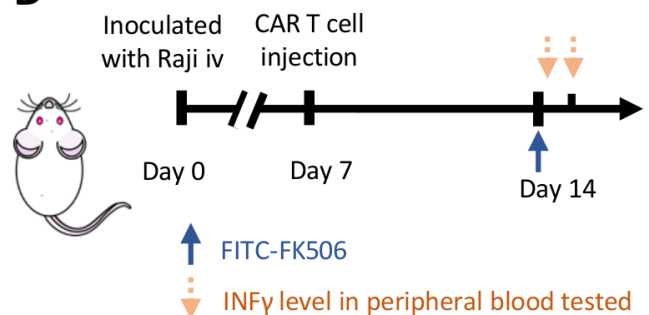

E

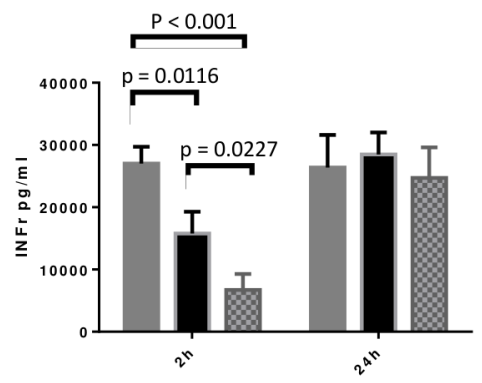

Figure 7 Suppression of a CAR T-mediated cytokine release syndrome (CRS) via use of the chimeric endocytosing receptor to deliver either a cytotoxic or immunosuppressive payload. (A) NSG mice were intravenously injected with $2 \times 10^{6}$ Raji cells on day 0 and then treated on day 7 with $10^{7}$ anti-CD19 CAR T cells containing the FITC-FR fusion receptor. Following emergence of CRS symptoms (significantly elevated plasma IFN $\gamma$ ), mice were injected on day 14 with a single dose of FITC-DM4 $(0.25 \mu \mathrm{mol} /$ $\mathrm{kg}$ or $0.5 \mu \mathrm{mol} / \mathrm{kg}$ ) and monitored for changes in IFN $\gamma$ levels (B) and CAR T numbers (C) at the indicated days (down arrows). (D) Alternatively, mice treated as above on days 0 and 7 were injected on day 14 with a single dose of FITC-FK506 $(0.25 \mu \mathrm{mol} / \mathrm{kg}$ or $0.5 \mu \mathrm{mol} / \mathrm{kg}$ ) and monitored for changes in IFN $\gamma$ levels both 2 hours and 24 hours after treatment (E). $n=5$ mice per group. All data represent mean $\pm \mathrm{SE},{ }^{*}$ denotes a $p$-value $<0.05,{ }^{*}<0.01$. CAR, chimeric antigen receptor; FITC-FR, FK506 binding protein folate receptor; IFN $\gamma$, interferon- $\gamma$.

and decrease associated IFN $\gamma$ levels without causing systemic toxicity. As seen in figure 7B, human IFN $\gamma$ (ie, CAR T cell-derived IFN $\gamma$ ) began to decline immediately after FITC-DM4 injection and continued to drop until the experiment was terminated. Not surprisingly, CAR T cell numbers also declined with similar kinetics, suggesting that the diminution of IFN $\gamma$ likely arose from killing of the human CAR T cells. More importantly, although non-targeted DM4 was observed to increase serum aspartate transaminase concentrations (ie, a marker of liver damage), FITC-DM4 induced no elevation in aspartate transaminase above control mice (online supplemental figure S3). Because only 0.25 umoles $/ \mathrm{kg}$ FITC-DM4 was sufficient to reduce cytokine expression and since the CAR receptors do not saturate until $\sim 0.8-1.0 \mu \mathrm{mol} / \mathrm{kg},{ }^{26}$ occupancy of all receptors was not required to achieve a significant biological effect.

To test the ability of a non-cytotoxic FITC conjugate of FK506 to suppress CAR T cell activities without terminating the CAR T cell therapy, we next treated a similar cohort of NSG tumor-bearing mice with an FITC conjugate of FK506; that is, a non-lethal suppressor of CAR T cell activity (figure 7D). As shown in figure 7E, IFN $\gamma$ levels decreased dramatically within 2 hours of FITC-FK506 administration, but increased to pretreatment levels by 24 hours postadministration. These data demonstrate that a transient inhibition of CAR T cell activity can be achieved through use of a FITCtargeted non-toxic inhibitor of $\mathrm{T}$ cell activity, allowing the user to decide the duration and magnitude of CAR T cell suppression via control of the timing and concentration of FITC-FK506 administered.

\section{DISCUSSION}

Although adoptive cell therapies (ACTs) provide attractive options for treatment of many diseases, their translation into the clinic has been limited by an inability to control their activities following reinfusion into patients. Thus, overactivated CAR $\mathrm{T}$ cells can generate lethal concentrations of cytokines, ${ }^{27}$ while exhausted CAR T cells can adapt to comfortably coexist with cancer cells. ${ }^{28}$ Genetically modified ACTs can transform into malignant cells if inserted genes alter control of oncogenes ${ }^{29} 30$ and transplanted stem cells can differentiate into unwanted cell types when microenvironmental signals alter their intended differentiation. ${ }^{31}{ }^{32}$ Because drugs that might otherwise regulate ACTs have no specificity for ACT cell types, only drugs that have little or no systemic toxicity can be exploited to manipulate the behaviors of re-infused ACTs. While the recent use of dasatinib to suppress a CRS appears to constitute a safe method to control the excessive release of toxic cytokines ${ }^{33} 34$ no obvious remedy exists to differentiate, rejuvenate, proliferate or otherwise modulate the properties of ACTs in vivo. To address this problem, we have engineered a 'CER' that will allow delivery of any drug selectively into an ACT, 
thereby avoiding the potential toxicity associated with uptake of the same drug by healthy cells throughout the body. Thus, when ACT activity must be terminated, the re-infused cells plus all of their progeny can be killed by delivery of a cytotoxic drug through the ACT-specific CER. Similarly, when a cell therapy becomes exhausted, overactivated, underdifferentiated or wrongly differentiated, its properties can be analogously manipulated by targeting of the appropriate modulators specifically to the CER-expressing ACT; that is, regardless of the effect of the same modulator on other cells in the body. Because patient safety constitutes a major criterion on which FDA authorization depends, an ability to control multiple ACT properties by use of a single fusion protein could prove critical to ACT approval. While activation of suicide genes has already been explored for termination of ACTs, ${ }^{9}$ when less terminal manipulations of cell behavior are desired, the use of a CER constitutes an excellent option.

In our design of a CER, we desired a receptor that would: (1) express at a high level in any ACT cell type, (2) traffic to the exoplasmic surface of this cell type, (3) recycle rapidly through nonlysosomal compartments back to the cell surface, (4) be composed of primarily of human components to minimize antigenicity, (5) contain a binding site for a low molecular weight targeting ligand that would have no other binding site in the body and (6) exhibit very high affinity for this targeting ligand. Use of human FR $\alpha$ for the recycling domain assured criteria 1-4 (12), while use of either FKBP or human scFv against fluorescein largely satisfied criteria 4-6. Most other high affinity protein-ligand interactions required either use of a non-human component (eg, the streptavidin-biotin interaction) or would have been compromised by additional binding sites existing on non-ACT cells (eg, a cannabinoid receptor). Although concern might have still arisen over a possible interaction between an FK506drug conjugate and an intracellular FKBP (ie, all FKBPs that bind FK506 are intracellular), this apprehension has been allayed by both designing our ligand-drug conjugates to be membrane impermeable, thereby preventing their interaction with cells lacking a surface-exposed FKBP. While either fusion protein could turn out to be immunogenic, following humanization of the antiFITC scFv, the only non-human peptides that could be presented in an HLA-restricted manner would reside at the junction between the two human domains, thus minimizing the probability of immunogenicity.

Although most envisioned applications of this CER strategy occur in the area of ACT regulation, it did not escape our attention that the same receptor might be exploited for imaging, detection and quantitation of ACTs. Thus, when the number, location, pharmacokinetics or pharmacodynamics of a transplanted cell type must be monitored, delivery of a radiolabeled payload with selective affinity for the ACT should allow an accurate method for their quantitation. Thus, in cases where a transplanted CAR T, islet, or stem cell might appear to lose efficacy, a decrease in cell number might be distinguished from a decline in cell activity by administering a radiolabeled conjugate of FITC or FK506 and determining the number of ACT cells remaining in the tissue. With the remedies for a decrease in ACT number differing from the remedies for a decline in ACT activity, information on the cause of any diminution in activity can be useful.

\section{MATERIALS AND METHODS \\ Cell lines and human T cells}

RPMI 1640 (Gibco) containing 10\% heat-inactivated fetal bovine serum and $1 \%$ penicillin-streptomycin was used for culture of Raji and Jurkat cell lines. DMEM (Gibco) containing $10 \%$ heat-inactivated fetal bovine serum and $1 \%$ penicillin-streptomycin was employed for culture of MDA-MB-231 and MDA-MB-231 CD19 ${ }^{+}$cells. Peripheral blood mononuclear cells (PBMCs) were isolated by Ficoll density gradient centrifugation (GE Healthcare Lifesciences) of whole human blood obtained from healthy volunteers. Pure $\mathrm{CD}^{+} \mathrm{T}$ cells were enriched from PBMCs using an EasySep Human T Cell Isolation Kit (STEM CELL technologies) and then cultured in TexMACS medium (Miltenyi Biotech) containing $1 \%$ penicillin and streptomycin sulfate plus 2\% human serum (Valley Biomedical) in the presence of human interleukin 2 (IL-2) $(100 \mathrm{IU} / \mathrm{mL}$, Miltenyi Biotech). Human T cells were counted every 2-3 days and maintained at $0.5 \times 10^{6}$ cells $/ \mathrm{mL}$. All cells were cultured in $5 \% \mathrm{CO}_{2}$ at $37^{\circ} \mathrm{C}$ and were regularly tested for contamination of mycoplasma.

\section{Preparation and use of lentiviral vectors encoding anti-CD19 CAR T2A FKBP-FR and anti-CD19 CAR T2A FITC-FR}

For coexpression of a classical anti-CD19 $\mathrm{CAR}^{35}$ together with our CER fusion protein in the same human $T$ cell, a lentiviral vector was constructed containing genes for the above two proteins linked via a T2A selfcleaving sequence. ${ }^{18}$ For preparation of the gene for the FKBP-containing a CER (FKBP-FR), a construct of the following sequences in frame from 5' to 3' end was prepared: residues 1-24 of human (FR $\alpha$, NM_016724.2), the entire sequence for human FKBP12 (NM_000801.5), the sequence of a flexible peptide linker (GGGGS), and the sequence for the remainder of human FR $\alpha$ (residues 25-257) (see figure 1C). For coexpression of this gene in the same vector as the anti-CD19 CAR, the sequence for the anti-CD19 CAR was ligated in frame to the sequence for the T2A self-cleaving peptide, ${ }^{17}$ which in turn was ligated in frame to the sequence for FKBP-FR (figure 1D). The resulting construct was then inserted into a pHR lentiviral expression vector by restriction enzyme digestion with MluI and NotI, and then human $\mathrm{T}$ cells were transfected with the lentiviral vector using standard methods. ${ }^{36}$ Briefly, purified human T cells were first activated using Dynabeads coupled to anti-CD3/ CD28 antibodies (Life Technologies) for 12-24hours in the presence of human IL-2 $(100 \mathrm{IU} / \mathrm{mL})$ and then infected with the aforementioned lentivirus. After 3-5 days of transfection, ${ }^{37}$ the $\mathrm{T}$ cells were harvested and 
analyzed by flow cytometry to establish that $\sim 70 \%$ of the $\mathrm{CD} 3+\mathrm{T}$ cells were expressing a CER. The antifluorescein scFv containing CER (FITC-FR) was prepared similarly, except the sequence for the anti-FITC $\mathrm{scFv}^{14}$ was used instead of the sequence for FKBP.

\section{Synthesis, purification and analytical characterization of FK506 and FITC derivatives}

See text in Supporting Information.

\section{CER binding and internalization assays}

For analysis of FK506-rhodamine binding to CERexpressing cells, FKBP-FR transfected Jurkat cells or non-transfected cells $\left(5 \times 10^{5}\right)$ were preincubated in the presence or absence of FK506-glucosamine (100-fold excess to block all available fusion receptors) for $30 \mathrm{~min}$ at $4^{\circ} \mathrm{C}$, and then incubated with the indicated concentration of FK506-rhodamine again for $30 \mathrm{~min}$ at $4{ }^{\circ} \mathrm{C}$. Cells were washed three times, then resuspended in $2 \%$ FBS PBS and submitted for analysis by flow cytometry. The binding affinity assays for FITC-AlexFluor 647 were determined similarly, except 100-fold excess FITC-glucosamine was employed as the competitor. For analysis of the effect of PI-PLC treatment, cells were removed from the monolayer with scrapers and washed in PBS, then suspended at $5 \times 10^{6}$ cells $/ \mathrm{mL}$ in $0.025 \mathrm{M}$ Tris- $\mathrm{HCl}, 0.25 \mathrm{M}$ sucrose, $0.01 \mathrm{M}$ glucose, $1 \times$ protease inhibitor cocktail (Roche), $\mathrm{pH}$ 7.5. $100 \mu \mathrm{L}$ of the cell suspension were then incubated with 5 units of PI-PLC (ThermoFisher, \#P6466) at $37^{\circ} \mathrm{C}$ for 1 hour, after which the reaction was stopped by cooling to $4^{\circ} \mathrm{C}$. Cells were then washed and analyzed for FK506rhodamine or FITC-AlexFluor 647 binding by incubation with the above conjugates at $4^{\circ} \mathrm{C}$ following by washing in PBS and analysis by flow cytometry. Results were evaluated using FlowJo software. GraphPad Prism V.7 software was used to analyze binding affinity.

For evaluation of ligand-drug conjugate internalization, $1 \times 10^{4}$ FKBP-FR expressing HEK293 cells in $0.5 \mathrm{~mL}$ of growth media were seeded in covered glass chambers (ThermoFisher, \#155383) and incubated overnight at 37 ${ }^{\circ} \mathrm{C}$ to achieve full adherence. Fresh medium containing $50 \mathrm{nM}$ FK506-rhodamine was then added, and cells were further incubated either at $4^{\circ} \mathrm{C}$ or $37^{\circ} \mathrm{C}$ for the times indicated. Cells were then washed with warm cell medium and imaged using a confocal laser scanning microscope. The internalization assay for the FITC-FR fusion receptor was performed similarly, except FITC-AlexFluor 647 was used as the ligand-drug conjugate.

\section{Quantification of CER expression using FA- ${ }^{99 m} \mathrm{Tc}$}

A folate complex of ${ }^{99 \mathrm{~m}} \mathrm{Tc}\left(\mathrm{EC} 20{ }^{99 \mathrm{~m}} \mathrm{Tc}\right)$ was prepared as previously described. ${ }^{38} \mathrm{~KB}$, FKBP-FR Jurkat or FITC-FR Jurkat cells were then grown in a 24 -well plates and incubated with $50 \mathrm{nM}$ EC20- ${ }^{99 \mathrm{~m}} \mathrm{Tc}$ at $4{ }^{\circ} \mathrm{C}$ for $30 \mathrm{~min}$. After incubation, the cells were washed and lysed in 10\% SDS solution, and the radiation level of each sample was determined using a gamma counter.
Measurement of internalized and membrane-bound FITC${ }^{99 \mathrm{~m}} \mathrm{Tc}$

FITC- ${ }^{99 \mathrm{~m}}$ Tc was synthesized and chelated with technetium similar to EC20- ${ }^{99 \mathrm{~m}} \mathrm{Tc}$ (see Supporting Information). To quantitate the amount of surface-bound and internalized FITC $-{ }^{99 \mathrm{~m}}$ Tc following incubation with HEK293 cells expressing FITC-FR, cells were seeded at $\sim 30 \%$ confluence and cultured for $\sim 2$ days in 24-well plates and then incubate with FITC- ${ }^{99 \mathrm{~m}}$ Tc for the desired times at either four or $37^{\circ} \mathrm{C}$. Cells were then washed with PBS and lysed in $0.5 \mathrm{~mL} 10 \% \mathrm{SDS}$ solution. The radiation levels of each sample were then determined with a gamma counter.

\section{Characterization of FITC-FR and FKBP-FR fusion receptor molecular weights by Western blotting}

Expression of FITC-FR and FKBP-FR in HEK293 cells was evaluated by lysing the cells in SDS-PAGE solution and centrifuging the solution at $16000 \mathrm{xg}$ for $10 \mathrm{~min}$ at $4^{\circ} \mathrm{C}$ to remove any residual debris. Supernatants were then resolved by electrophoresis on $4 \%-20 \%$ SDS-PAGE gels and electrophoretically transferred to nitrocellulose filters. Blots were probed with anti-FR $\alpha$ or antiactin antibody, followed by staining with horseradish peroxidaseconjugated secondary antibody. Stained blots were then visualized using the enhanced chemiluminescence method.

\section{Analysis of cell killing using FITC-maytansine (DM4) ligand- drug conjugate}

Human T cells transfected with FITC-FR were incubated for 2 hours at $37^{\circ} \mathrm{C}$ with different concentrations of an FITC-targeted conjugate of the potent cytotoxin, maytansine DM4 in either the absence or presence of 100-fold excess of FITC-glucosamine (competition). Cells were then washed twice, supplemented with fresh medium, and cultured for another 72 hours. CellTiter-Glo ${ }^{\mathrm{TM}}$ reagent (Promega, \#G7570) was then added to each well at a 1:1 $\mathrm{vol} / \mathrm{vol}$ ratio and luminescent readings were obtained to determine cell viability using a plate reader according to the manufacture's protocol.

\section{Inhibition of human T cell lysis of cancer cells using an FK506 conjugate of either FITC or FK506}

Anti-CD19 CAR T cells coexpressing either FITC-FR or FKBP-FR were cocultured with CD19-expressing Raji cells at an effector : target cell ratio of 5:1. FITC-FK506 or FK506-FK506 was then added to the coculture and the incubation was continued for an additional 2 hours in the absence or presence of competing ligands (FITCglucosamine or FK506-glucosamine). Cells were then washed, supplemented with fresh medium and the incubation was continued for an additional 12 hours. Culture plates were then centrifuged at $350 \times \mathrm{g}$ for $10 \mathrm{~min}$, and supernatants were assayed for both cancer cell death by evaluating released lactate dehydrogenase activity using CytoONE (Promega) and IFN $\gamma$ levels using human IFN $\gamma$ ELISA kit (BioLegend). 
Evaluation of the biodistribution of CER positive CAR T cells with FITC $-{ }^{99 m}$ Tc conjugate

To quantify the biodistribution of CER expressing antiCD19 CAR T cells in vivo, a CD19-expressing murine solid tumor model was desired. For this purpose, MDAMB-231 human breast cancer cells were transfected with lentivirus encoding CD19 (NM_001178098.1), and $10^{6}$ MDA-MB-231 CD19 ${ }^{+}$cells were implanted subcutaneously in immunodeficient NSG mice (Jackson Laboratory). After allowing the tumors to grow to $\sim 100 \mathrm{~mm}^{3}$, $\sim 10^{7}$ anti-CD19 FITC-FR CAR T cells were intravenously injected and permitted to redistribute and proliferate naturally for 2 weeks. Two hundred $\mu \mathrm{Ci}$ of FITC- ${ }^{99 \mathrm{~m}} \mathrm{Tc}$ dissolved in $100 \mu \mathrm{L}$ PBS was then intravenously injected and 4 hours later all major organs were collected and counted by gamma counting. Tumor volumes were estimated using a caliper and the equation $\mathrm{V}=1 / 2\left(\mathrm{~L} \mathrm{x} \mathrm{W}^{2}\right)$, where $\mathrm{L}$ is the longest axis of the tumor and $\mathrm{W}$ is the axis perpendicular to $\mathrm{L}$.

\section{Evaluation of FITC-DM4 and FITC-FK506 on FITC-FR CAR T cell activity in a Raji tumor model}

Immunodeficient NSG mice (Jackson Laboratory) were implanted intravenously with $2 \times 10^{6}$ Raji cells (a CD19 positive lymphoma cell line). Seven days later, mice were injected intravenously with $10^{7}$ FITC-FR anti-CD19 CAR $\mathrm{T}$ cells and bodyweights were monitored every other day. Seven days after CAR T cell injection, FITC-DM4 or FITC-FK506 was administered intravenously and peripheral blood IFN $\gamma$ levels were assayed at the times indicated using an IFN $\gamma$ ELISA kit (BioLegend). Peripheral blood human CAR T cell numbers were similarly determined in peripheral blood samples by c-myc-APC staining, followed by by flow cytometry in the presence of counting beads.

Acknowledgements The authors would like to acknowledge the Purdue Center for Cancer Research, the Purdue Institute for Drug Discovery, the Purdue Flow Cytometry Core and the Chemical Genomic Facility for their services. This work was funded by a gift from the Hurvis Family Foundation.

Contributors BZ contributed to the design of study, acquisition of in vitro and in vivo data, analysis/interpretation of data, and writing of the manuscript. PSL conceived of the concept and contributed to the design of study, analysis/ interpretation of data, writing of the manuscript, and supervision of the project. QL conducted the toxicity study. JVN, XL and MS designed and synthesized related molecules. All authors edited and approved the final manuscript.

Funding This work was funded by a gift from the Hurvis Family Foundation.

Competing interests None declared.

Patient consent for publication Not required.

Ethics approval All animal care and use were followed by NIH guidelines, and all experimental protocols were approved by the Purdue Animal Care and Use Committee.

Provenance and peer review Not commissioned; externally peer reviewed.

Data availability statement All data relevant to the study are included in the article or uploaded as online supplemental information.

Supplemental material This content has been supplied by the author(s). It has not been vetted by BMJ Publishing Group Limited (BMJ) and may not have been peer-reviewed. Any opinions or recommendations discussed are solely those of the author(s) and are not endorsed by BMJ. BMJ disclaims all liability and responsibility arising from any reliance placed on the content. Where the content includes any translated material, BMJ does not warrant the accuracy and reliability of the translations (including but not limited to local regulations, clinical guidelines, terminology, drug names and drug dosages), and is not responsible for any error and/or omissions arising from translation and adaptation or otherwise.

Open access This is an open access article distributed in accordance with the Creative Commons Attribution Non Commercial (CC BY-NC 4.0) license, which permits others to distribute, remix, adapt, build upon this work non-commercially, and license their derivative works on different terms, provided the original work is properly cited, appropriate credit is given, any changes made indicated, and the use is non-commercial. See http://creativecommons.org/licenses/by-nc/4.0/.

\section{ORCID iDs}

Boning Zhang http://orcid.org/0000-0001-8516-137X

Madduri Srinivasarao http://orcid.org/0000-0003-3056-4571

\section{REFERENCES}

1 Wakitani S, Imoto K, Yamamoto T, et al. Human autologous culture expanded bone marrow mesenchymal cell transplantation for repair of cartilage defects in osteoarthritic knees. Osteoarthritis Cartilage 2002;10:199-206.

2 Ramiya VK, Maraist M, Arfors KE, et al. Reversal of insulindependent diabetes using islets generated in vitro from pancreatic stem cells. Nat Med 2000;6:278-82.

3 Funakoshi S, Miki K, Takaki T, et al. Enhanced engraftment, proliferation, and therapeutic potential in heart using optimized human iPSC-derived cardiomyocytes. Sci Rep 2016;6:19111.

4 Mandai M, Watanabe A, Kurimoto Y, Takahashi M, et al. Autologous induced Stem-Cell-Derived retinal cells for macular degeneration. $N$ Engl J Med 2017;376:1038-46.

5 Banchereau J, Palucka AK. Dendritic cells as therapeutic vaccines against cancer. Nat Rev Immunol 2005;5:296-306.

6 Lu W, Arraes LC, Ferreira WT, et al. Therapeutic dendritic-cell vaccine for chronic HIV-1 infection. Nat Med 2004;10:1359-65.

7 Davila ML, Riviere I, Wang X, et al. Efficacy and toxicity management of 19-28z CAR T cell therapy in B cell acute lymphoblastic leukemia. Sci Transl Med 2014;6:ra225.

8 Greco R, Oliveira G, Stanghellini MTL, et al. Improving the safety of cell therapy with the TK-suicide gene. Front Pharmacol 2015;6:95.

9 Straathof KC, Pulè MA, Yotnda P, et al. An inducible caspase 9 safety switch for T-cell therapy. Blood 2005;105:4247-54.

10 Wu C-Y, Roybal KT, Puchner EM, et al. Remote control of therapeutic $\mathrm{T}$ cells through a small molecule-gated chimeric receptor. Science 2015;350:aab4077

11 Cyrus K, Wehenkel M, Choi E-Y, et al. Two-headed PROTAC: an effective new tool for targeted protein degradation. Chembiochem 2010;11:1531-4.

12 Bandara NA, Hansen MJ, Low PS. Effect of receptor occupancy on folate receptor internalization. Mol Pharm 2014;11:1007-13.

13 Kozany C, März A, Kress C, et al. Fluorescent probes to characterise FK506-binding proteins. Chembiochem 2009;10:1402-10.

14 Midelfort KS, Hernandez HH, Lippow SM, et al. Substantial energetic improvement with minimal structural perturbation in a high affinity mutant antibody. J Mol Biol 2004;343:685-701.

15 Dunyak BM, Gestwicki JE. Peptidyl-Proline isomerases (PPlases): targets for natural products and natural product-inspired compounds. J Med Chem 2016;59:9622-44.

16 Kolos JM, Voll AM, Bauder M, et al. FKBP Ligands-Where we are and where to go? Front Pharmacol 2018;9:1425.

$17 \mathrm{Kim} \mathrm{JH}$, Lee S-R, Li L-H, et al. High cleavage efficiency of a $2 \mathrm{~A}$ peptide derived from porcine teschovirus- 1 in human cell lines, zebrafish and mice. PLoS One 2011;6:e18556.

18 Berger J, Howard AD, Brink L, et al. COOH-terminal requirements for the correct processing of a phosphatidylinositol-glycan anchored membrane protein. J Biol Chem 1988;263:10016-21.

19 Low PS, Henne WA, Doorneweerd DD. Discovery and development of folic-acid-based receptor targeting for imaging and therapy of cancer and inflammatory diseases. Acc Chem Res 2008;41:120-9.

20 Ruella M, Xu J, Barrett DM, et al. Induction of resistance to chimeric antigen receptor $T$ cell therapy by transduction of a single leukemic $B$ cell. Nat Med 2018;24:1499-503.

21 Lambert JM, Morris CQ. Antibody-Drug conjugates (ADCs) for personalized treatment of solid tumors: a review. Adv Ther 2017;34:1015-35.

22 Srinivasarao M, Galliford CV, Low PS. Principles in the design of ligand-targeted cancer therapeutics and imaging agents. Nat Rev Drug Discov 2015;14:203-19.

23 Sakuma S, Kato Y, Nishigaki F, et al. FK506 potently inhibits T cell activation induced TNF-alpha and IL-1beta production in vitro 
by human peripheral blood mononuclear cells. Br J Pharmacol 2000;130:1655-63.

24 Terpstra V, van Berkel TJ. Scavenger receptors on liver Kupffer cells mediate the in vivo uptake of oxidatively damaged red blood cells in mice. Blood 2000;95:2157-63.

25 Lee YG, Chu H, Lu Y, et al. Regulation of CAR T cell-mediated cytokine release syndrome-like toxicity using low molecular weight adapters. Nat Commun 2019;10:1-11.

26 Paulos CM, Reddy JA, Leamon CP, et al. Ligand binding and kinetics of folate receptor recycling in vivo: impact on receptor-mediated drug delivery. Mol Pharmacol 2004;66:1406-14.

27 Porter D, Frey N, Wood PA, et al. Grading of cytokine release syndrome associated with the CAR T cell therapy tisagenlecleucel. J Hematol Oncol 2018;11:35.

28 Mognol GP, Spreafico R, Wong V, et al. Exhaustion-associated regulatory regions in $\mathrm{CD}^{+}$tumor-infiltrating T cells. Proc Natl Acad Sci U S A 2017;114:E2776-85.

29 Baum C, Düllmann J, Li Z, et al. Side effects of retroviral gene transfer into hematopoietic stem cells. Blood 2003;101:2099-113.

30 Wu C, Dunbar CE. Stem cell gene therapy: the risks of insertional mutagenesis and approaches to minimize genotoxicity. Front Med 2011;5:356-71.

31 Bauer G, Elsallab M, Abou-El-Enein M. Concise review: a comprehensive analysis of reported adverse events in patients receiving unproven stem cell-based interventions. Stem Cells Transl Med 2018;7:676-85.
32 Woodworth CF, Jenkins G, Barron J, et al. Intramedullary cervical spinal mass after stem cell transplantation using an olfactory mucosal cell autograft. CMAJ 2019;191:E761-4.

33 Weber EW, Lynn RC, Sotillo E, et al. Pharmacologic control of CAR-T cell function using dasatinib. Blood Adv 2019;3:711-7.

34 Mestermann K, Giavridis T, Weber J, et al. The tyrosine kinase inhibitor dasatinib acts as a pharmacologic on/off switch for CAR T cells. Sci Trans/ Med 2019;11:eaau5907.

35 Kochenderfer JN, Feldman SA, Zhao Y, et al. Construction and preclinical evaluation of an anti-CD19 chimeric antigen receptor. $J$ Immunother 2009;32:689-702.

36 Salmon P, Kindler V, Ducrey O, et al. High-level transgene expression in human hematopoietic progenitors and differentiated blood lineages after transduction with improved lentiviral vectors. Blood 2000;96:3392-8.

37 Duong CPM, Westwood JA, Yong CSM, et al. Engineering T cell function using chimeric antigen receptors identified using a DNA library approach. PLoS One 2013;8:e63037.

38 Leamon CP, Parker MA, Vlahov IR, et al. Synthesis and biological evaluation of EC20: a new folate-derived, (99m)Tc-based radiopharmaceutical. Bioconjug Chem 2002;13:1200-10.

39 Yang J, Chen $\mathrm{H}$, Vlahov IR, et al. Evaluation of disulfide reduction during receptor-mediated endocytosis by using FRET imaging. Proc Natl Acad Sci U S A 2006;103:13872-7. 